\title{
The effect of intake of water on the final values of body composition parameters in active athletes using two different bioimpedance analyzers
}

\author{
Petr Kutáč \\ Human Motion Diagnostic Center, University of Ostrava, Ostrava, Czech Republic
}

Copyright: @ 2014 P. Kutáč. This is an open access article licensed under the Creative Commons Attribution License (http://creativecommons.org/licenses/by/4.0/).

\begin{abstract}
Background: The method of bioelectrical impedance (BIA) is frequently used to estimate body composition in sports. The total body water (TBW) is the basic variable that BIA measures. That implies the degree of sensitivity of BIA to the hydration of the organism, which is also demonstrated by the principles of measurement that primarily relate to the hydration of the organism. It is difficult to provide standard hydration of the organism of subjects prior to measurements when taking the measurements in the field. Objective: The objective of the study is to assess the changes in the final values of the selected body composition parameters in soccer players caused by intake of water, using two devices commonly used in the field. Methods: The research was performed in a group of 33 soccer players (mean age $20.30 \pm 1.18$ years). The measurements were taken using Tanita BC $418 \mathrm{MA}$ (frequency $50 \mathrm{kHz}$ ) and Nutriguard-M (frequency $100 \mathrm{kHz}$ ). To evaluate the effect of water intake, we took two measurements before and after the intake of $500 \mathrm{ml}$ of water. The parameters measured by Tanita BC 418 MA were body weight (BW), total body water (TBW), body fat (BF), fat free mass (FFM). Nutriguard-M was used to measure total body water (TBW), intra and extracellular water (ICW and ECW), body fat (BF), fat free mass (FFM), intra and extracellular mass (BCM and ECM). The differences in the means $\left(M_{1}\right.$ and $\left.M_{2}\right)$ of the monitored parameters were evaluated using the Paired Samples t-test. In statistically significant differences in the mean, the practical significance was also verified using the effect of size (Cohen's $d$ ). Results: The Tanita device showed statistically significant differences after the intake of $500 \mathrm{ml}$ in parameters BW $(+0.42 \mathrm{~kg}), \mathrm{BF}(+0.39 \mathrm{~kg},+0.53 \%)$ and TBW $(-0.38 \%)$. As for the Nutriguard device, statistically significant differences were found in parameters TBW $(+0.77 \mathrm{~kg}), \mathrm{ICW}(+0.83 \mathrm{~kg})$, FFM $(+1.05 \mathrm{~kg})$, BCM $(+0.79 \mathrm{~kg})$ and ECM/BCM (-0.01). Conclusion: The water intake had no effect on the final value of the body composition parameters, which was confirmed by the low effect of size values $(d=0.06-0.47)$ of parameters where statistically significant differences were found. Also, the water intake had no effect on the accuracy of measurement of both devices. The measurements of the standard error of measurements values before and after the water intake did not differ.
\end{abstract}

Keywords: soccer players, body weight, body water, body fat, fat free mass, repeated measurement

\section{Introduction}

The current functional diagnostics of athletes is an integral part of a successful training process (McArdle, Katch, \& Katch, 2007). The diagnostics not only evaluate functional prerequisites, but they also look at the morphological predispositions of the individual. The assessment of morphological predispositions usually focuses on the evaluation of body composition that may determine, to some extent, the level of readiness of the athlete's organism for the training and competitive

\footnotetext{
* Address for correspondence: Petr Kutáč, Human Motion Diagnostic Center, University of Ostrava, Varenská 40a, 70200 Ostrava, Czech Republic. E-mail: petr.kutac@osu.cz
}

load. It is also possible to assess the effect of physical exercise on the organism and evaluate its adequacy by monitoring changes in body composition (Bauer, Pivarnik, Fornetti, Jallo, \& Nassar, 2005; Green, Pivarnik, Carrier, \& Womack, 2006; Quinney et al., 2008; Rahimi, 2006; Sanchez, Sanz, \& Zabala, 2007).

Field methods are most often used to assess body composition in regular sports practice. At present, the method of bioelectrical impedance (BIA) is used very often (Heymsfield, Lohman, Wang, \& Going, 2005). This method is based on the use of the various properties of tissue, fat and particularly body water. Since fat free mass contains a high proportion of water and electrolytes, it is a good conductor, unlike fat tissue that functions as an insulator and bad conductor. The 
current passes through water and electrolyte components in the fat free mass and the resulting resistance is thus proportional to its volume. The value of the tissue resistance (bioelectrical impedance) is inversely proportional to the volume of tissue which the electric current passes through. The values of the individual body composition parameters are then calculated from the impedance values using regressive equations (Heyward \& Wagner, 2004). The description of the principle of the method shows that total body water (TBW) is the basic variable that BIA measures. That also implies sensitivity of BIA to hydration of the organism, which is also documented by the principles of measurement mainly concerning hydration of an organism (Malina, Bouchard, \& Or, 2004; McArdle, Katch, \& Katch, 2007). In order to provide standard conditions for measurement and thus the most precise result of measurement, the principles of measurement must be strictly observed.

The provision of standard hydration of the subjects' organisms prior to the practical execution of measurement in the field is a problem. In order to facilitate the provision of other conditions of standard measurement related to food intake, alcohol and physical exercise (Heyward \& Wagner, 2004), the measurements are usually taken in the morning and subjects thus come to the laboratory from their homes without prior checks (e.g. by trainers). Therefore, we have to rely on their statements claiming that they have observed all the conditions for measurement when we verify the observation of the principles of measurement and thus the intake of fluids. A similar situation occurs when measurement concerns a larger number of subjects (e.g. football or ice-hockey team) when individual subjects have to wait for the measurement and may take in fluids during such waiting time. With regard to the fact that Bunc (2007) stated that a change in the hydration of organism concerning the intake or loss of fluids in the volume of $500 \mathrm{ml}$ has an effect on the values of impedance in roughly 10 minutes, such a change should be reflected in the resulting values of the monitored parameters. The question is how large such a change is and whether or not it may lead to misinterpretation of the measured results, e.g. in repeated measurement with the objective to assess the effect of external intervention (e.g. a training program) on the athlete's body composition.

The objective of the study is to assess the changes in the final values of the selected body composition parameters in soccer players caused by intake of water, using two devices commonly used in the field.

\section{Methodology}

\section{The research group}

The research group consisted of soccer players from the registered list of teams playing the top junior soccer competition in the Czech Republic. The total number of tested athletes was 33 men with an average age of $20.3 \pm 1.18$ years.

The study protocol was approved by the Ethics and Research Committee of the University of Ostrava. All participants signed an informed consent form.

\section{Procedures}

All measurements took place in the morning, with strict observance of the principles of measurement that mainly concern the hydration of the organism. The participants did not drink any alcohol and did not exercise twelve hours prior to the measurement and they had been fasting when they arrived. The information about the observance of the aforementioned principles was checked using a questionnaire prior to the commencement of the first measurement. The measurements were all taken by the same person with corresponding qualification. The parts of the body of each proband which were in contact with the measuring electrodes were dried out for the body composition measurement. The basic anthropometric parameters of the subjects were measured during the initial measurement (body height, body weight and calculated BMI). The measurement of the body composition was executed using two devices based on the method of bioelectrical impedance. The first device was the Tanita BC 418 MA tetrapolar bio-impedance scale (Tanita, Japan) that uses the frequency of $50 \mathrm{kHz}$. The Tanita device also measured body weight. The second device used was the Nutriguard-M multi-frequency bioelectric impedance analyzer (DataInput, Germany) that uses the frequency of up to $100 \mathrm{kHz}$. The body was defined as a five-cylinder model for the measurement by both devices; the model does not include the head (the head is not included in the calculation). The Tanita device monitored the values of the representation of fat mass (BF), total body water (TBW) and fat free mass (FFM); the Nutriguard device monitored the same parameters that were supplemented with the values of extracellular water (ECW) and intracellular water (ICW), extracellular mass (ECM) and intracellular mass (BCM). Each proband underwent 2 measurements by each of the used devices. The measurements on both devices were executed at the same time. After the first measurement, $M_{1}$ proband took in $500 \mathrm{ml}$ of unflavored potable water within 10 to 12 minutes. This range was determined with regard to the findings by Bunc (2007). The range was also chosen with regard to the organization of 
measurement when it was not possible to ensure that each proband was measured precisely 10 minutes after the water intake with regard to the number of subjects. The subjects were lying down for 10 minutes prior to the measurement by Nutriguard-M, as that is the measuring position for this device. The reason is to prevent changes (shifts) between the extra and intracellular space that could be caused due to a fast change in the position.

\section{Statistical analysis}

Remote observations were identified using box plots; the normality of distribution was checked using the Shapiro-Wilk test. The accuracy of the individual measurements was assessed using the standard error of measurements (SE). Since all the monitored parameters showed normal distribution, the Paired samples $t$-test was used to evaluate whether or not the difference in the means of the measured value before and after the intake of fluids differs from 0 , e.g. the change in the measured value after the intake is significant.

In parameters where statistical significance of the differences in the means was determined, we also assessed practical significance of the results of the means and standard deviations. To evaluate practical significance, we used the Effect of Size (ES) according to Cohen (1988):

$d=\frac{M_{1}-M_{2}}{S D}$, where $S D=\sqrt{\frac{n_{1} \cdot S D_{1}^{2}+n_{2} \cdot S D_{2}^{2}}{n_{1}+n_{2}}}$

$M_{1}, M_{2}=$ mean values of the sets, $\mathrm{n}_{1}, \mathrm{n}_{2}=$ frequency of the sets, $S D_{1}, S D_{2}=$ standard deviations of the sets).

Recommendation for the size of effect according to Cohen's $d$ : 0.2 = minor change; 0.5 = medium change; $0.8=$ major change (Cohen, 1988). We consider the value of Cohen's $d$ at 0.5 and higher to be a substantively significant difference.

To express the level of correlation between the $M_{1}$ and $M_{2}$ results in the monitored parameters, we used the intraclass correlation coefficient (ICC) and the Pearson correlation coefficient ( $r$ ) (Thomas, Nelson, $\&$ Silverman, 2005). To assess the effect of the factors of the water intake and the device used on the final values of the monitored parameters, we used the twoway analysis of variance for repeated measurements (2 ANOVA). This effect was only evaluated in parameters that could be measured by both devices (BF, TBW and FFM). The selected level of statistical significance for all the tests used was determined to be $\alpha=.05$. The results were processed statistically using the SPSS Statistics 19.0 program.

\section{Results}

This section presents the mean values of the initial measurement $\left(M_{1}\right)$ of the monitored parameters as well as the changes in the values of the results after the intake of $500 \mathrm{ml}$ of water $\left(M_{2}\right)$. Table 1 presents the values of the basic anthropometric parameters.

Table 1

Input anthropometric parameters

\begin{tabular}{lc}
\hline Parameter & $M \pm S D$ \\
\hline BH $(\mathrm{cm})$ & $178.69 \pm 6.30$ \\
BW $(\mathrm{kg})$ & $73.88 \pm 6.98$ \\
BMI $\left(\mathrm{kg} / \mathrm{m}^{2}\right)$ & $23.13 \pm 1.62$ \\
\hline
\end{tabular}

Note. $\mathrm{BH}=$ body height, $\mathrm{BW}=$ body weight, $\mathrm{BMI}=$ body mass index.

\section{Tanita BC 418 MA Results}

Table 2 presents the results of the mean values of $M_{1}$ and $M_{2}$ of the monitored parameters, their differences and the statistical analysis.

The intake of $500 \mathrm{ml}$ of water resulted in an increase in the BW mean value by $0.42 \mathrm{~kg}$. Since TBW did not increase at the same time (and there was also a minimum increase in the FFM mean value in $\mathrm{kg}$ ), the $\mathrm{BF}$ mean value increased $(\mathrm{kg}, \%)$. Both $\mathrm{BF}$ and BW increases in $M_{2}$ were statistically significant (BW $\mathrm{kg}: p<.001$, BF kg, \%: $p<.05$ ); however, practical significance was not demonstrated with regard to the ES values (the $d$ values ranged from 0.06 to 0.15 ).

The standard deviation of the mean (SE) of the $M_{1}$ and $M_{2}$ values that we used to quantify the inaccuracy of our measurement almost did not differ. It appears that the device measured the individual parameters before and after the intake of $500 \mathrm{ml}$ of water with the same accuracy.

The $r$ values found in the individual parameters in $M_{1}$ and $M_{2}$ measurements exceed .90 (.93-1.00) which is high, almost a linear correlation dependency. The $r$ values thus explain the fluctuation exceeding $86 \%$. Figure 1-5 shows the graphic illustration of $r$ in the individual parameters.

\section{Nutriguard-M results}

This device not only measures the representation of $\mathrm{BF}$, FFM and TBW, but also ECM and BCM, including the calculation of the index of this mass (ECM/ BCM), and also ICW and ECW. The mean values of the individual monitored parameters from $M_{1}$ and $M_{2}$, including their differences and the statistical analysis, are presented in Table 2.

The increase of BW by $0.42 \mathrm{~kg}$ was reflected in the increase of TBW by $0.77 \mathrm{~kg}(p<.01)$, which was 


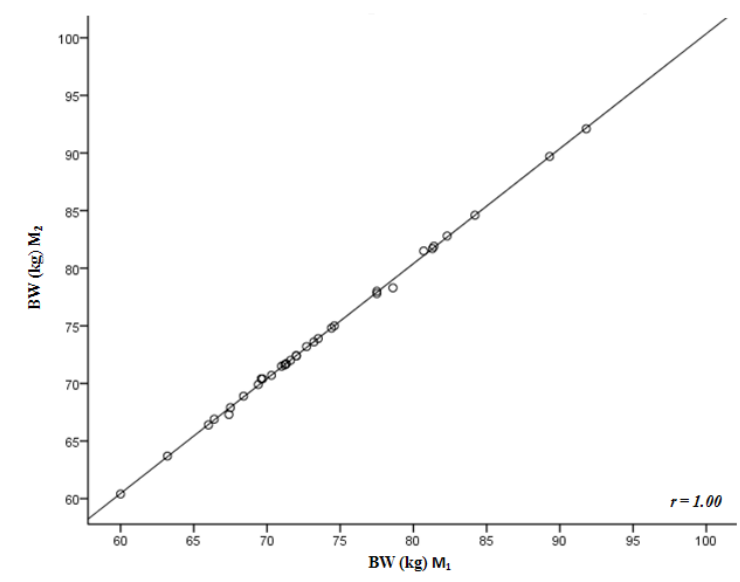

Figure 1. Correlation between the values of parameters measured by Tanita before and after the intake of fluids - body weight $(\mathrm{kg})$

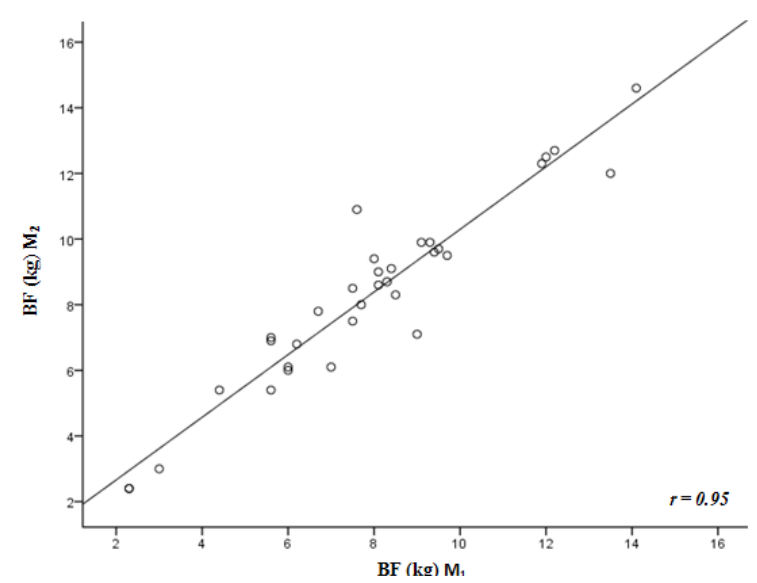

Figure 2. Correlation between the values of parameters measured by Tanita before and after the intake of fluids - body fat $(\mathrm{kg})$

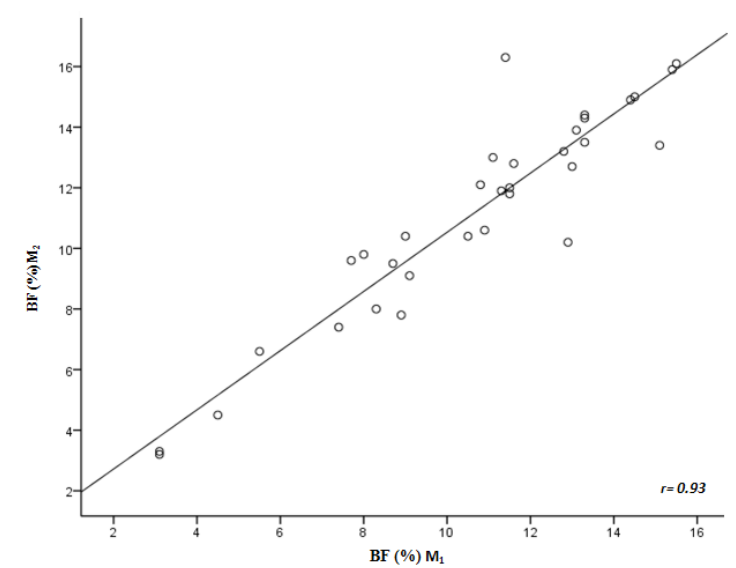

Figure 3. Correlation between the values of parameters measured by Tanita before and after the intake of fluids - body fat (\%)



Figure 4. Correlation between the values of parameters measured by Tanita before and after the intake of fluids - total body water $(\mathrm{kg})$



Figure 5. Correlation between the values of parameters measured by Tanita before and after the intake of fluids - fat free mass $(\mathrm{kg})$ 
Table 2

Descriptive results of the monitored parameters measured before and after the intake of fluids

\begin{tabular}{|c|c|c|c|c|c|c|c|c|}
\hline Parameter & $M_{1} \pm S D_{1}$ & $M_{2} \pm S D_{2}$ & $\mathrm{SE}\left(\right.$ of $\left.M_{1}\right)$ & SE (of $M_{2}$ ) & Diff. & $d$ & $r$ & $I C C$ \\
\hline \multicolumn{9}{|l|}{ Tanita } \\
\hline BW (kg) & $73.88 \pm 6.98$ & $74.30 \pm 6.97$ & 1.14 & 1.14 & $+0.42 * * *$ & 0.06 & 1.00 & 1.00 \\
\hline $\mathrm{BF}(\mathrm{kg})$ & $7.79 \pm 2.86$ & $8.18 \pm 2.87$ & 0.49 & 0.49 & $+0.39 *$ & 0.13 & .95 & .95 \\
\hline $\mathrm{BF}(\%)$ & $10.51 \pm 3.37$ & $11.04 \pm 3.50$ & 0.57 & 0.60 & $+0.53^{*}$ & 0.15 & .93 & .93 \\
\hline TBW (kg) & $48.10 \pm 4.43$ & $48.10 \pm 4.59$ & 0.76 & 0.78 & $0.00^{\mathrm{ns}}$ & - & .99 & .99 \\
\hline FFM (kg) & $65.70 \pm 6.06$ & $65.72 \pm 6.28$ & 1.04 & 1.07 & $+0.02^{\mathrm{ns}}$ & - & .99 & .99 \\
\hline \multicolumn{9}{|l|}{ Nutriguard } \\
\hline $\mathrm{BF}(\mathrm{kg})$ & $10.90 \pm 3.92$ & $10.27 \pm 3.68$ & 0.66 & 0.62 & $-0.63^{\mathrm{ns}}$ & - & .83 & .82 \\
\hline $\mathrm{BF}(\%)$ & $14.57 \pm 4.32$ & $13.67 \pm 4.15$ & 0.73 & 0.70 & $-0.90^{\mathrm{ns}}$ & - & .77 & .77 \\
\hline TBW (kg) & $46.10 \pm 3.85$ & $46.87 \pm 4.06$ & 0.65 & 0.68 & $+0.77 * *$ & 0.19 & .93 & .93 \\
\hline $\mathrm{ECW}(\mathrm{kg})$ & $19.03 \pm 2.54$ & $18.97 \pm 2.51$ & 0.43 & 0.42 & $-0.06^{\mathrm{ns}}$ & - & .99 & .99 \\
\hline ICW (kg) & $27.07 \pm 1.86$ & $27.90 \pm 1.66$ & 0.31 & 0.28 & $+0.83 * *$ & 0.47 & .63 & .66 \\
\hline FFM (kg) & $62.98 \pm 5.26$ & $64.03 \pm 5.56$ & 0.89 & 0.94 & $+1.05^{* *}$ & 0.19 & .92 & .93 \\
\hline ECM $(\mathrm{kg})$ & $26.19 \pm 2.98$ & $26.45 \pm 3.20$ & 0.50 & 0.54 & $+0.26^{\mathrm{ns}}$ & - & .96 & .96 \\
\hline BCM (kg) & $36.80 \pm 2.99$ & $37.59 \pm 3.02$ & 0.50 & 0.51 & $+0.79 * *$ & 0.26 & .90 & .90 \\
\hline $\mathrm{ECM} / \mathrm{BCM}$ & $0.71 \pm 0.06$ & $0.70 \pm 0.06$ & 0.01 & 0.01 & $-0.01 *$ & 0.16 & .96 & .95 \\
\hline
\end{tabular}

Note. $M_{1}=$ measurement before the intake of fluids, $M_{2}=$ measurement after intake of fluids, $S D_{1}, S D_{2}=$ standard deviation, $\mathrm{SE}=$ standard error of measurement, Diff. = difference $\left(M_{1}-M_{2}\right), d=$ effect of size, $r=$ Pearson correlation coefficient, $I C C=$ intraclass correlation coefficient. $\mathrm{BW}=$ body weight, $\mathrm{BF}=$ body fat, $\mathrm{TBW}=$ total body water, $\mathrm{FFM}=$ fat free mass, $\mathrm{ECW}=$ extracellular water, $\mathrm{ICW}=$ intracellular water, $\mathrm{ECM}=$ extracellular mass, $\mathrm{BCM}=$ intracellular mass. ${ }^{*} p<.05,{ }^{* *} p<.01, * * * p<.001,{ }^{\text {ns }}$ not significant.

reflected in the increase of FFM by $1.05 \mathrm{~kg}(p<.01)$, of which TBW is a part. As for the TBW components, the ratio of ICW increased by $0.83 \mathrm{~kg}(p<.01)$, which led to an increase in $\mathrm{BCM}(\mathrm{kg})(p<.01)$ greater than ECM $(\mathrm{kg})$. The differences were statistically significant; however, practical significance was not demonstrated with regard to the ES values (the $d$ values ranged from 0.16 to 0.47 ), which also corresponds to the differences found in the mean values ( $\mathrm{M}_{1}$ vs. $\left.\mathrm{M}_{2}\right)$.

Like Tanita BC $418 \mathrm{MA}$, the SE values in $M_{1}$ and $M_{2}$ almost do not differ. The measurements by Nutriguard-M after the intake of $500 \mathrm{ml}$ of water were taken with similar accuracy.

The $r$ values also ranged from .63 to .99 . That explains the fluctuation from approximately $40 \%$ to $99 \%$. The lowest $r$ value was determined in ICW $\mathrm{kg}$ (.63). Six parameters (TBW kg, ECW, FFM, ECM, $\mathrm{BCM}$ and $\mathrm{ECM} / \mathrm{BCM}$ ) demonstrated high correlation dependency between $M_{1}$ and $M_{2}$ that reached or exceeded the value of .90 . The graphic illustration of correlations is presented in Figure 6-14.

Effect of the factors of water intake and used device - 2 ANOVA results

Table 3 presents the results of the significance of the intake of water, the used device and the interaction of both factors. The results show that only the used device has an effect on the final mean value of the monitored parameters during the repeated measurement. The intake of water or interaction of both factors had no effect. The significance values are greater than the selected level of statistical significance $(\alpha=.05)$. The fact that the interaction of the two factors - intake of water vs. used device - has no significant effect on the results means that the results provided by both devices before and after the intake of water do not differ significantly.

Table 3

\section{ANOVA results}

\begin{tabular}{lccc}
\hline & \multicolumn{3}{c}{ Significance } \\
\cline { 2 - 4 } Parameter & Device & $\begin{array}{c}\text { Water } \\
\text { intake }\end{array}$ & $\begin{array}{c}\text { Interaction } \\
\text { of factors }\end{array}$ \\
\hline BW (kg) & .828 & .727 & .999 \\
BF (kg) & $<.001$ & .857 & .470 \\
BF (\%) & $<.001$ & .795 & .382 \\
TBW (kg) & $\mathbf{. 0 1 3}$ & .617 & .685 \\
TBW (\%) & $<.001$ & .803 & .391 \\
FFM (kg) & $\mathbf{. 0 1 3}$ & .608 & .689 \\
\hline
\end{tabular}

Note. Statistically significant $p$ values are in boldface. 


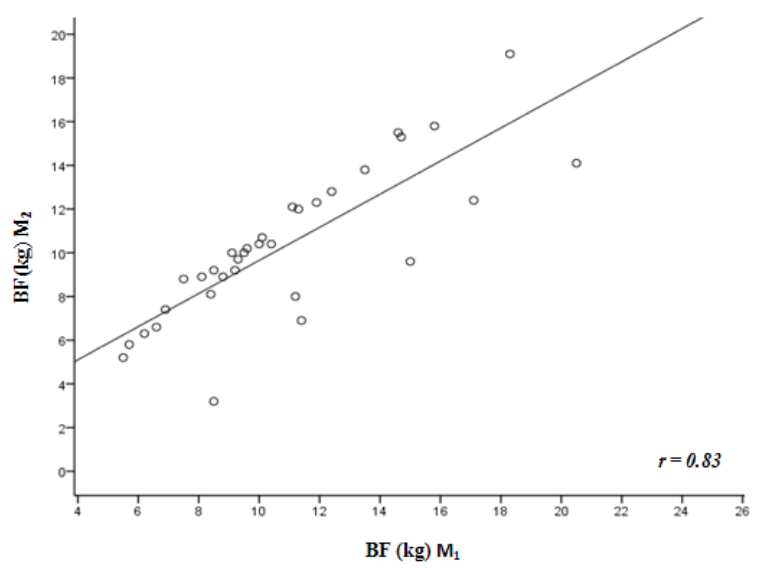

Figure 6. Correlation between the values of parameters measured by Nutriguard-M before and after the intake of fluids - body fat $(\mathrm{kg})$

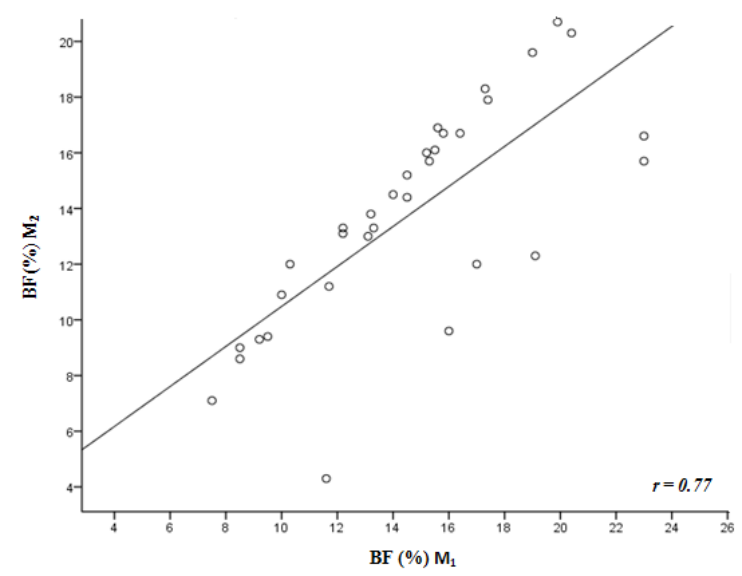

Figure 7. Correlation between the values of parameters measured by Nutriguard-M before and after the intake of fluids - body fat (\%)



Figure 8. Correlation between the values of parameters measured by Nutriguard-M before and after the intake of fluids - total body water $(\mathrm{kg})$

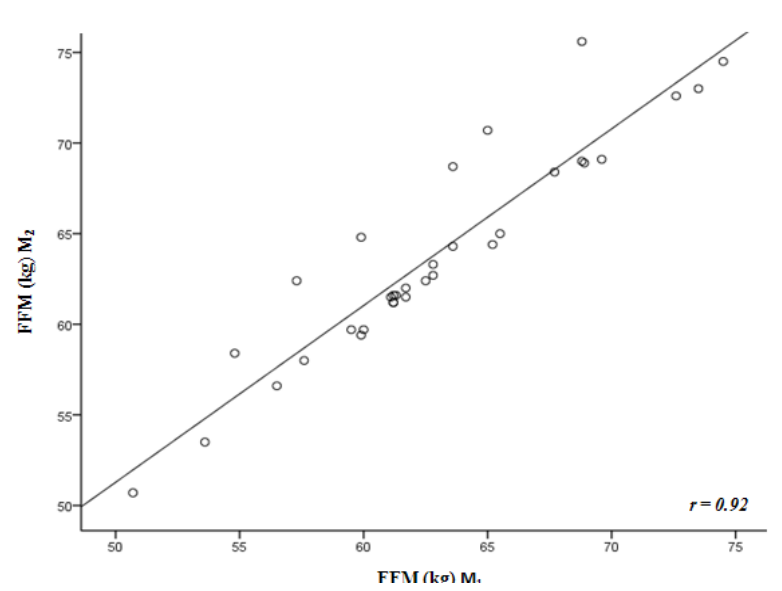

Figure 9 Correlation between the values of parameters measured by Nutriguard-M before and after the intake of fluids - fat free mass $(\mathrm{kg})$

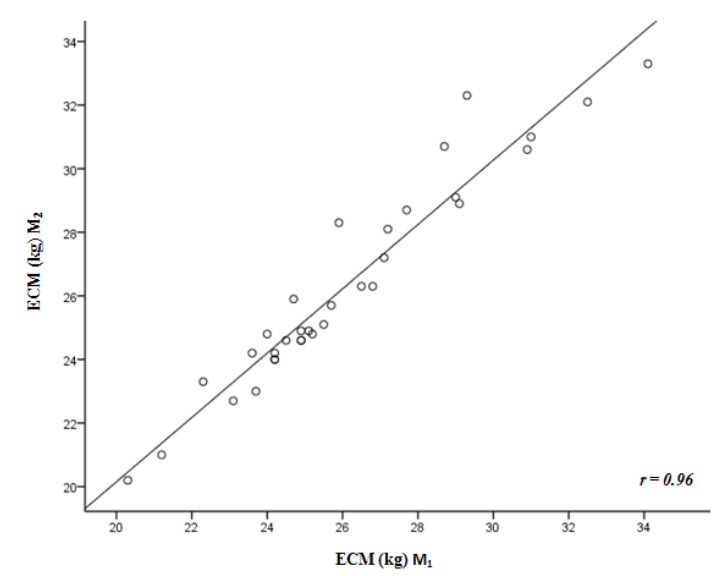

Figure 10. Correlation between the values of parameters measured by Nutriguard-M before and after the intake of fluids - extracellular mass $(\mathrm{kg})$

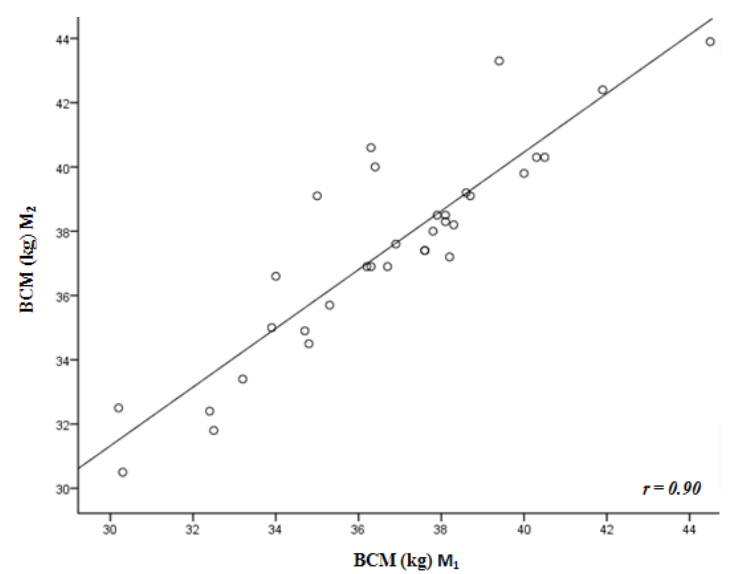

Figure 11. Correlation between the values of parameters measured by Nutriguard-M before and after the intake of fluids - body cell mass $(\mathrm{kg})$ 


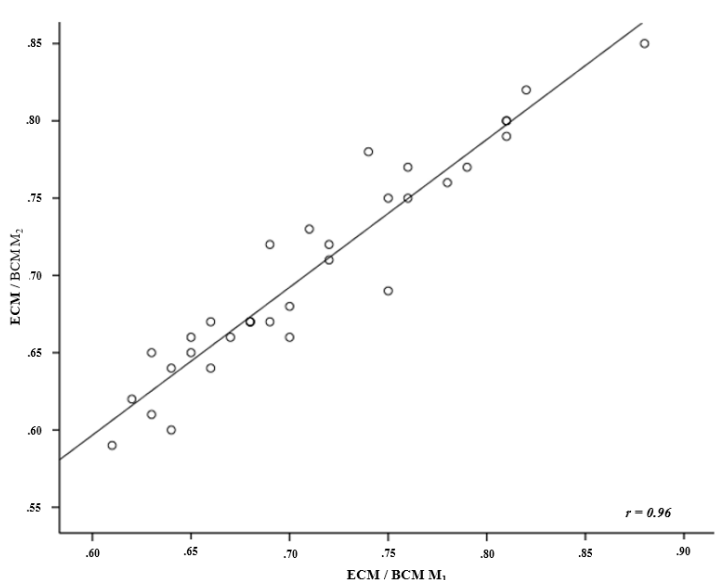

Figure 12. Correlation between the values of parameters measured by Nutriguard-M before and after the intake of fluids - index ECM/BCM

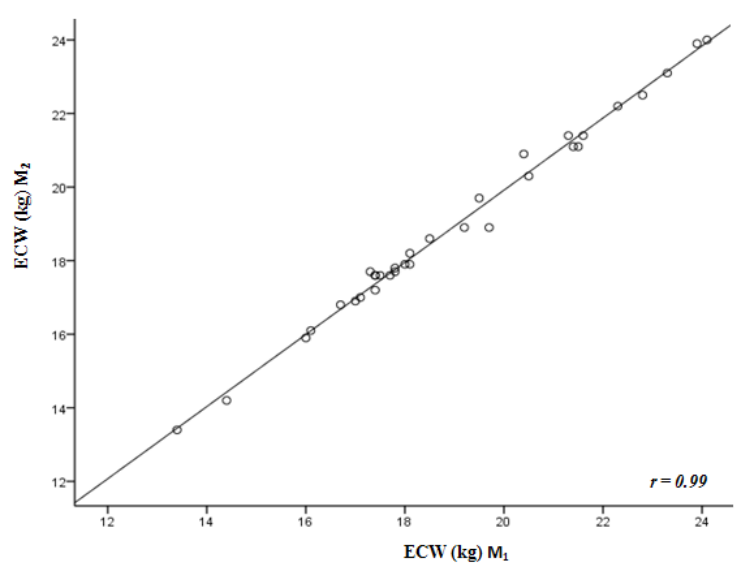

Figure 13. Correlation between the values of parameters measured by Nutriguard-M before and after the intake of fluids - extracellular water $(\mathrm{kg})$

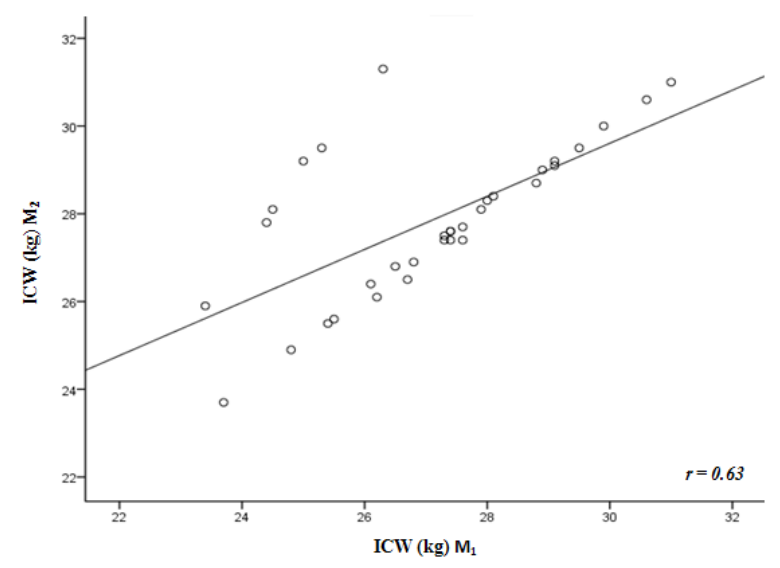

Figure 14. Correlation between the values of parameters measured by Nutriguard-M before and after the intake of fluids - intracellular water $(\mathrm{kg})$

\section{Discussion}

The mean value of the total body mass in the monitored participants did not increase by $0.5 \mathrm{~kg}$ after the intake of $500 \mathrm{ml}$ of water but only by $0.42 \mathrm{~kg}$. This difference was most likely caused by the error of measurement of Tanita BC 418 MA, which is also a scale. The missing $0.08 \mathrm{~kg}$ is within the intentions of determination of the standard error of measurement. Kutáč (2012) stated the standard error of measurement in soccer players of the same age at the level of $0.14 \mathrm{~kg}$. The result may also be influenced by the accuracy of measurement at $0.1 \mathrm{~kg}$ and by the number of participants. The mean value would be probably closer to the value of $0.5 \mathrm{~kg}$ if there were significantly more participants.

The changes of the mean body composition values measured by the Tanita BC 418 MA device after an increase in hydration correspond with the results presented in professional studies dealing with bioelectrical impedance. In spite of the fact that the studies mentioned used other devices than those applied in this study, there was also an increase in $\mathrm{BF}$, not in FFM. This increase ranged from $0.4 \%$ to $1.1 \%$ of $\mathrm{BF}$ in relation to the quantity of fluids used for hydration. The authors of the studies applied fluids in the range from $500 \mathrm{ml}$ to $1000 \mathrm{ml}$ to their subjects. The stated changes grew with the volume of fluids (Demura, Zamyji, Goshi, \& Nagasawa, 2002; Dixon, LoVallo, Andreacci, \& Goss, 2006; Heiss et al., 2009; O’Brien, Zouny, \& Sawka, 2002; Saunders, Blevins, \& Broeder, 1998; Uter, McAnulty, Riha, Pratt, \& Grose, 2012). A similar development of changes in the BF representation was also established when a different method was applied. Using plethysmography when hydrating subjects with water from $500 \mathrm{ml}$ to $2000 \mathrm{ml}$, Vukovich and Peeters (2003) also determined a similar increase in the body weight that had an effect on BF (from $0.34 \%$ to $2.33 \%$ ), but not on FFM. Heiss, Naylor, Bronco, and Myers (2008) who hydrated individuals using a quantity below $500 \mathrm{ml}$ in their study ( $350 \mathrm{ml}$ of milk), did not find any changes. We did not find any changes in the body composition established by Nutriguard-M when the increase in the total body weight after hydration affected the increase in FFM and TBW and decrease in $\mathrm{BF}$ in any of the aforementioned studies dealing with this matter. This could be caused by the different frequencies that the applied devices use. The aforementioned studies included BIA devices using the frequency of $50 \mathrm{kHz}$, while the Nutriguard-M device uses the frequency of $100 \mathrm{kHz}$. Due to the different position of measurement, the gravitational field could have had an effect on the redistribution of water. Since the equations used in the software of the devices are not available, it is very difficult to substantiate the 
different changes of the monitored parameters in the applied devices.

Knowing the differences in the individual measured parameters that may be caused by changes in the hydration of the organism is very important for the diagnostic practice and correct interpretation of the results of measurement, so that we can objectively assess, especially in case of repeated measurements after interventions (training program), what differences in the monitored parameters are caused by the intervention and what differences are caused by noncompliance with the conditions of measurement (changes in hydration). BF and FFM (or the ratio of FFM components: ECM/BCM) are parameters most frequently monitored by coaches in the field of sports. Therefore, we will focus on those parameters in greater detail.

The established differences in the mean values of the percentage representation of BF do not exceed the value of $2 \%$ of $\mathrm{BF}$, which is a limit value considered the optimal size of error and devices measuring with this error are considered to be very precise (Heyward $\&$ Wagner, 2004). Based on the stated optimal size of the error of measurement, we should consider a difference above $2 \%$ to be the actual change in the percentage representation of $\mathrm{BF}$. Therefore, the differences in the mean values after the increase in hydration that we established should be considered low. The level of $2 \%$ of BF was exceeded in 2 subjects (6\%) using Tanita BC $418 \mathrm{MA}$ and in 5 subjects $(15.1 \%)$ using Nutriguard-M. However, the final value of the BF percentage representation in studies that directly deal with the accuracy of measurement and errors of devices using the BIA method do not exceed 1\% (Kutáč, 2012; Kutáč \& Gajda, 2011; Macfarlane, 2007; Sung, Lau, Yu, Lam, \& Nelson, 2001). In our set, the mean difference between $M_{1}$ and $M_{2}$ did not exceed that value in any of the devices, which was also manifested by the failure to prove substantive significance also in Tanita BC 418 MA, where statistical significance was determined (the value of Cohen's $d=0.15$ ). A detailed analysis showed that the differences between $M_{1}$ and $M_{2}$ exceeding $1 \%$ were found in 8 subjects $(24.2 \%)$ measured by Tanita $418 \mathrm{MA}$ and in 9 subjects $(27.2 \%)$ measured by Nutriguard-M. The low values of errors in the measurement of the $\mathrm{BF}$ representation also correspond to the high values of correlation coefficients stated in professional studies dealing with the reliability of BF measurements. The values range from .86 to .99 (Kettaneh et al., 2005; Kilduff, Lewis, \& Kingsley, 2007; Lubans et al., 2011; Macfarlane, 2007). In particular, the $r$ values (.95 and $.93)$ and $I C C$ (.95 and .93) taken by the Tanita device corresponded with the aforementioned values. As for Nutriguard-M, the $r$ values (.83 and .77) and ICC (.82 and .77) were lower.
The error of measurement in the range from 2.0$2.5 \mathrm{~kg}$ is considered to be sufficiently precise for the FFM values (Heyward \& Wagner, 2004). Our results thus clearly show that the established differences in the mean values by both devices did not exceed this borderline. Same as the BF representation, the stated error of measurement was exceeded in 2 subjects $(6 \%)$ using Tanita BC 418 MA and in 5 subjects (15.1\%) using Nutriguard-M. The same number of subjects where the values of the optimal error of measurement were exceeded in BF and FFM corresponds with the calculation of those values that we used. The increase in the FFM representation was mainly caused by the increase in the body cell mass (BCM). The increase in the hydration resulted in an increase in the amount of cells that are able to use oxygen and oxidize carbohydrates, e.g. the cells that directly participate in the work of the muscles. However, this increase is misleading as the increase of hydration cannot be an actual cause of the increase in the number of those cells. Therefore, it is a change caused by the setting of the equation in the software of the device. With regard to the low Cohen's $d$ value (practical significance of the found difference) the increase found is insignificant in practice. That is also confirmed by the minimum difference between the $M_{1}$ and $M_{2}$ values in the ECM/BCM index used for assessing athletes' readiness. The change would have no effect on the individual assessment of the athlete's readiness either. The evaluation would be the same for both values $\left(M_{1}\right.$ and $\left.M_{2}\right)$. In both cases, the value showed high readiness, which is also confirmed by the values stated in the studies that use the aforementioned index for evaluation. The index value in elite summer biathletes was 0.70 for men and 0.73 for adolescent men (Psotta et al., 2007; Psotta, Svěráková, Bunc, Šeflová, \& Hráský, 2009).

\section{Limitations of the study}

We are aware of the fact that the results presented in this study may have been influenced by a series of factors that particularly include the quantity of water $(500 \mathrm{ml})$ the participants took in before the repeated measurement. Also, the selection and number of participants who were included in the diagnostics may be considered significant. When generalizing the results, we have to be very cautious. We are aware that the obtained results only apply to the used devices, the chosen age group and the sports specialization (soccer).

\section{Conclusions}

The consumed water had no effect on the final value of the body composition parameters $\left(M_{2}\right)$, which was 
confirmed by the low values of ES $(d=0.06-0.47)$ in parameters where statistically significant differences were established. Likewise, the consumed water had no effect on the accuracy of the measurement of the used devices. The SE values of $M_{1}$ and $M_{2}$ did not differ. The values of the Pearson correlation coefficient $r$ and intraclass correlation coefficient ICC were at a more or less similar level in all measurements. The $r$ values (1.00-.63) as well as the ICC values (1.00-.66) showed high correlation dependency between $M_{1}$ and $M_{2}$. The 2 ANOVA final values also did not confirm any potential effect of consumed water.

The differences in the parameters that are most frequently monitored in the diagnostic practice $(\mathrm{BF}$, FFM) were in the region of the errors of measurement of the used devices. Therefore, it seems that the intake of up to $500 \mathrm{ml}$ water by soccer players at the beginning of the adult age has not effect on the final values of the used devices.

The results obtained from Nutriguard-M show quite a fast transfer of water between the extra and intracellular space that occurred within 10-12 minutes after the intake of $500 \mathrm{ml}$ of water, which is confirmed by the lower values of ICC in ICW (.66), greater differentiation between $M_{1}$ and $M_{2}(+0.83 \mathrm{~kg})$ and the ES value that approximates the medium value (.47).

\section{Acknowledgments}

This work was supported by research project SGS 6120/PdF/2012.

\section{References}

Bauer, P. W., Pivarnik, J. M., Fornetti, W. C., Jallo, J. J., \& Nazdar, L. (2005). Cross validation of fat free mass prediction models for elite female gymnasts. Pediatric Exercise Science, 17, 337-344.

Bunc, V. (2007). Možnosti stanovení tělesného složení u dětí bioimpedanční metodou [Possibilities of determining children's body composition using the bioimpedance method]. Časopis lékařů českých, 146, 492-496.

Cohen, J. (1988). Statistical power analysis for the behavioral sciences (2nd ed.). Hillsdale, NJ: Lawrence Erlbaum Associates.

Demura, S., Zamyji, S., Goshi, F., \& Nagasawa, Y. (2002). The influence of transient change of total body water on relative body fats based on three bioelectrical impedance analyses methods. Comparison between before and after exercise with sweat loss, and after drinking. Journal of Sports Medicine \& Physical Fitness, 42, 38-44.

Dixon, C. B., LoVallo, S. J., Andreacci, J. L., \& Goss. F. L. (2006). The effect of acute fluid consumption on measures of impedance and percent body fat using leg to leg bioelectrical impedance analysis. European Journal of Clinical Nutrition, 60, 142-147.

Green, M. R., Pivarnik, J. M., Carrier, D. P., \& Womack, C. J. (2006). Relationship between physiological profiles and on-ice performance of a national collegiate athletic association division I Hockey Team. Journal of Strength and Conditioning Research, 20, 43-46.

Heiss, C. J., Gara, N., Novotny, D., Heberle, H., Morgan, L., Stufflebeam, J., \& Fairfield, M. (2009). Effect of a 1 liter fluid load on body composition measured by air displacement plethysmography and bioelectrical impedance. Journal of Exercise Physiology, 12(2), 1-8.

Heiss, C. J., Naylor, J., Bronco, K. M., \& Myers, B. (2008). A small food or fluid load has no effect on body composition measured by 3 different methods. Topics in Clinical Nutrition, 23, 229-233.

Heymsfield, S. B., Lohman, T. G., Wang, Z., \& Going, S. B. (2005). Human body composition. Champaign, IL: Human Kinetics.

Heyward, V. H, \& Wagner, D. R. (2004). Applied body composition assessment. Champaign IL: Human Kinetics.

Kettaneh, A., Heude, B., Lommez, A., Borys, J. M., Ducimetière, P., \& Charles, M. A. (2005). Reliability of bioimpedance analysis compared with other adiposity measurements in children: The FLVS II study. Diabetes \& Metabolism, 31, 534-541.

Kilduff, L. P., Lewis, S., \& Kingsley, M. I. (2007). Reliability and detecting change following short-term creatine supplementation: Comparison of two-component body composition methods. Journal of Strength and Conditioning Research, 21, 378-384.

Kutáč, P. (2012). Application of typical error of measurement for accuracy of measurement of body composition in athletes using the BIA method. Medicina Sportiva, 16, 150-154.

Kutáč, P., \& Gajda, V. (2011). Evaluation of accuracy of the body composition measurements by the BIA method. Human Movement, 12, 41-45.

Lubans, D. R., Morgan, P., Callister, R., Plotnikoff, R. C., Eather, N., Riley, N., \& Smith, C. J. (2011). Test-retest reliability of a battery of field-based health-related fitness measures for adolescents. Journal of Sports Sciences, 29, 685-693.

Macfarlane, D. J. (2007). Can bioelectric impedance monitors be used to accurately estimate body fat in Chinese adults? Asia Pacific Journal of Clinical Nutrition, 16(1), 66-73.

Malina, R. M., Bouchard, C., \& Or, O. B. (2004). Growth, maturation, and physical activity. Champaign IL: Human Kinetics.

McArdle, W. D., Katch, F. I., \& Katch, V. L. (2007). Exercise physiology. Energy, nutrition, and human performance. Philadelphia, PA: Lippincott Williams \& Wilkins.

O’Brien, C., Zouny, A. J., \& Sawka, M. N. (2002). Bioelectrical impedance to estimate changes in hydration status. International Journal of Sports Medicine, 23, 361-366.

Psotta, R., Bunc, V., Tenney, D., Svěráková, D., Hráský, P., \& Šeflová I. (2007). Physiological profile of Czech elite summer biathletes of both sexes. Gazzetta Medica Italiana, 166, 169-179. 
Psotta, R., Svěráková, D., Bunc, V., Šeflová, I., \& Hráský, P. (2009). Aerobic fitness, running performance and body composition of Czech elite male summer biathletes. International Journal of Fitness, 5(1), 41-49.

Quinney, H. A., Dewart, R., Game, A., Snydmiller, G., Warburton, D., \& Bell, G. (2008). A 26 year physiological description of a National Hockey League team. Applied Physiology, Nutrition, and Metabolism, 33, 753-760.

Rahimi, R. (2006). Effect of moderate and high intensity weight training on the body composition of overweight men. Facta Universitatis: Series Physical Education \& Sport, 4, 93-101.

Sanchez, M. C., Sanz, D., \& Zabala, M. (2007). Anthropometric characteristics, body composition and somatotype of elite junior tennis players. British Journal of Sports Medicine, 41, 793-799.

Saunders, M. J., Blevins, J. E., \& Broeder, C. E. (1998). Effects of hydration changes on bioelectrical impedance in endurance trained individuals. Medicine \& Science in Sports \& Exercise, 30, 885-892.

Sung, R., Lau, P., Yu, C., Lam, P., \& Nelson, E. (2001). Measurement of body fat using leg to leg bioimpedance. Archives of Disease in Childhood, 85, 263-267.

Thomas, J. R., Nelson, J. K., \& Silverman, S. J. (2005). Research methods in physical activity. Champaign, IL: Human Kinetics.

Uter, A. C., McAnulty, S. R., Riha, B. F., Pratt, B. A., \& Grose, J. M. (2012). The validity of multifrequency bioelectrical impedance measures to detect changes in the hydration status of wrestlers during acute dehydration and rehydration. Journal of Strength and Conditioning Research, 26, 9-15.

Vukovich, M. D., \& Peeters, B. M. (2003). Reliability of airdisplacement plethysmography in detecting body composition changes after water ingestion and after creatine supplementation. Journal of Exercise Physiology, 6, 115-122. 